\title{
A single-center experience of 1500 lung transplant patients
}

\author{
Keki R. Balsara, MD, ${ }^{a}$ Alexander S. Krupnick, MD, ${ }^{b}$ Jennifer M. Bell, RN, ${ }^{a}$ Ali Khiabani, MD, ${ }^{a}$ \\ Masina Scavuzzo, RN, BSN, ${ }^{c}$ Ramsey Hachem, MD, ${ }^{\mathrm{c}}$ Elbert Trulock, MD, ${ }^{\mathrm{c}}$ Chad Witt, MD, \\ Derek E. Byers, MD, PhD, ${ }^{\mathrm{c}}$ Roger Yusen, MD, ${ }^{\mathrm{c}}$ Bryan Meyers, MD, MPH, ${ }^{\mathrm{a}}$ Benjamin Kozower, MD, ${ }^{\mathrm{a}}$ \\ G. Alexander Patterson, MD, ${ }^{\mathrm{a}}$ Varun Puri, MD, MSCI, ${ }^{\mathrm{a}}$ and Daniel Kreisel, MD, $\mathrm{PhD}^{\mathrm{a}}$
}

\begin{abstract}
Objective: Over the past 30 years, lung transplantation has emerged as the definitive treatment for end-stage lung disease. In 2005, the lung allocation score (LAS) was introduced to allocate organs according to disease severity. The number of transplants performed annually in the United States continues to increase as centers have become more comfortable expanding donor and recipient criteria and have become more facile with the perioperative and long-term management of these patients. We report a single-center experience with lung transplants, looking at patients before and after the introduction of LAS.
\end{abstract}

Methods: We retrospectively reviewed 1500 adult lung transplants at a single center performed between 1988 and 2016. Patients were separated into 2 groups, before and after the introduction of LAS: group 1 (April 1988 to April 2005; 792 patients) and group 2 (May 2005 to September 2016; 708 patients).

Results: Differences in demographic data were noted over these periods, reflecting changes in allocation of organs. Group 1 patient average age was $48 \pm 13$ years, and 404 subjects $(51 \%)$ were male. Disease processes included emphysema $(52 \%$; $412)$, cystic fibrosis $(18.2 \% ; 144)$, pulmonary fibrosis $(16.1 \% ; 128)$ and pulmonary vascular disease $(7.2 \% ; 57)$. Double lung transplant $(77.7 \% ; 615)$ was performed more frequently than single lung transplant $(22.3 \% ; 177)$. Group 2 average age was $50 \pm 14$ years, and 430 subjects $(59 \%)$ were male. Disease processes included pulmonary fibrosis $(46 \% ; 335)$, emphysema $(25.8 \% ; 188)$, cystic fibrosis $(17.7 \%$; $127)$ and pulmonary vascular disease $(1.6 \% ; 11)$. Double lung transplant $(96.2 \%$; 681 ) was performed more frequently than single lung transplant $(3.8 \%$; 27). Overall incidence of grade 3 primary graft dysfunction (PGD) in group 1 was significantly lower at $22.1 \%(175)$ than in group 2 at $31.6 \%(230)(P<.001)$. Nonetheless, overall hospital mortality was not statistically different between the 2 groups $(4.4 \%$ vs $3.5 \% ; P<.4)$. Most notably, survival at 1 year was statistically different at 646 $(81.6 \%)$ for group 1 and $665(91.4 \%)$ for group $2(P<.02)$.

Conclusions: Patient demographics over the study period have changed with an increased number of fibrotic patients transplanted. In addition, more aggressive strategies with donor/recipient selection appear to have resulted in a higher incidence of primary graft dysfunction. This does not, however, appear to affect patient survival on index hospitalization or at 1 year. In fact, we have observed a significant improvement in survival at 1 year in the more recent era. This observation suggests that continued expansion of possible donors and recipients, coupled with a more sophisticated understanding of primary graft dysfunction and long-term chronic rejection, can lead to increased transplant volume and prolonged survival. (J Thorac Cardiovasc Surg 2018;156:894-905)

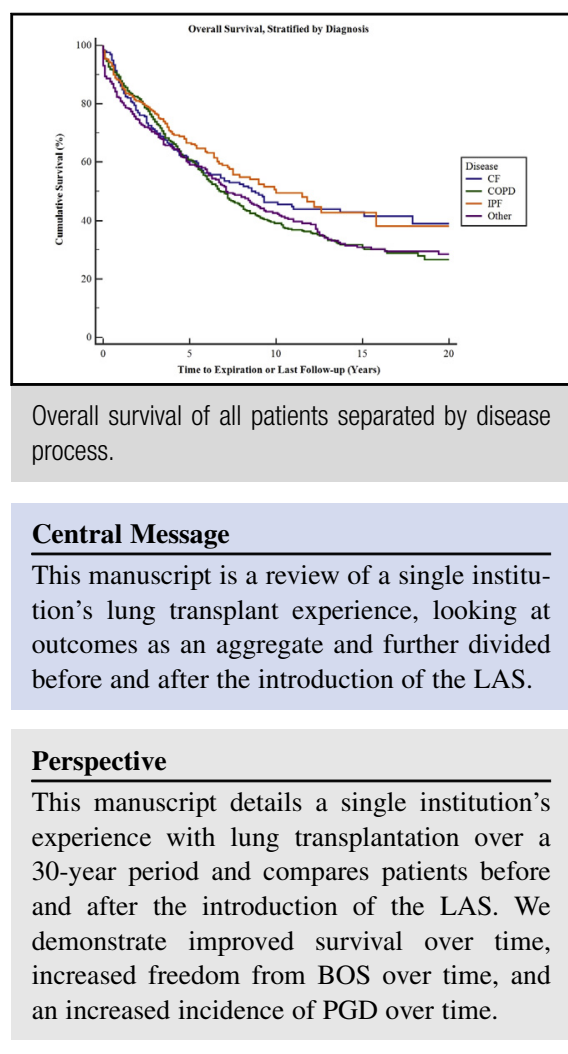

See Editorial Commentary page 906.

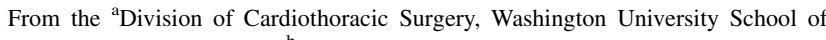
Medicine, St. Louis, Mo; ${ }^{b}$ Division of Cardiothoracic Surgery, University of Virginia School of Medicine, Charlottesville, Va; and ${ }^{\mathrm{c}}$ Division of Pulmonary and Critical Care Medicine, Washington University School of Medicine, St. Louis, Mo. Read at the 97th Annual Meeting of The American Association for Thoracic Surgery, Boston, Massachusetts, April 29-May 3, 2017

Received for publication July 23, 2017; revisions received Feb 28, 2018; accepted for publication March 3, 2018; available ahead of print June 8, 2018.
Address for reprints: Keki R. Balsara, MD, Division of Cardiothoracic Surgery, Washington University, 660 S Euclid Ave, \#8234, St. Louis, MO 63110 (E-mail: kekirbalsara@yahoo.com). 0022-5223/\$36.00

Copyright (C) 2018 by The American Association for Thoracic Surgery https://doi.org/10.1016/j.jtcvs.2018.03.112 

Abbreviations and Acronyms
BOS = bronchiolitis obliterans syndrome
COPD $=$ chronic obstructive pulmonary disease
$\mathrm{ECMO}=$ extracorporeal membrane oxygenaton
IPF $=$ interstitial pulmonary fibrosis
LAS = lung allocation score
PGD = primary graft dysfunction

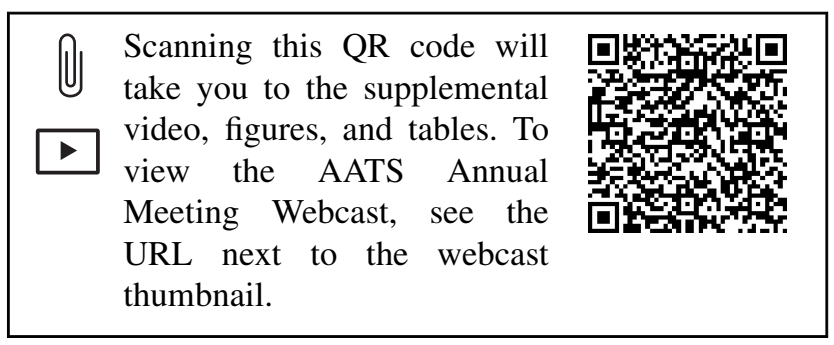

Lung transplantation remains the only durable long-term therapy for individuals suffering from end-stage lung disease. The Registry of the International Society of Heart and Lung Transplantation reports that 4080 lung transplants were performed nationwide in $2014 .{ }^{1}$ Over more than 3 decades, the field of lung transplantation has continued to evolve. With improvements in operative technique, refinement in postoperative management and a greater understanding of donor and recipient selection criteria, we have witnessed continued growth in the field. Nonetheless, long-term outcomes following lung transplantation have lagged behind other solid organs. The field faces numerous challenges which include, but are not limited to, a shortage of donor organs, a relatively high incidence of primary graft dysfunction (PGD) and a high rate of chronic graft failure from bronchiolitis obliterans syndrome (BOS). Our group has previously reported the incidence and outcomes of complications in 706 adult and 277 pediatric lung transplant patients. $^{2}$ More recently, we described the short- and long-term outcomes of 1000 adult lung transplant recipients at our institution. ${ }^{3}$ This current manuscript reports our experience with 1500 adult lung transplants that were performed at a single institution over a nearly 30 -year period. We look at the evolution of patient selection in the era of the lung allocation score (LAS) and what implications that has on short- and long-term survival.

\section{MATERIALS AND METHODS \\ Patient Demographics}

One thousand five hundred adult lung transplants were performed at the Barnes Jewish Hospital and Washington University School of Medicine in St. Louis between July 1988 and August 2016. Results were analyzed retrospectively using a prospectively gathered database of our lung transplant program. Permission for this study was obtained from the Washington University in St. Louis Institutional Review Board.

Table 1 shows demographic data for all patients. These data are broken down in to 2 groups, before and after the initiation of the lung allocation score, in Table 2. For all 1500 patients, mean recipient age was $48.9 \pm 13$ years. A total of 822 patients $(55 \%)$ were male and 678 patients $(45 \%)$ were female. We performed bilateral lung transplants in 1296 $(86.4 \%)$ patients and single lung transplants in $204(13.6 \%)$ patients. Thirty-three patients underwent retransplantation. Two patients were bridged to transplant with venovenous extracorporeal membrane oxygenation (ECMO). For purposes of this analysis, we excluded patients who received combined heart-lung transplants or lobar transplants. A total of 595 transplants $(39.7 \%)$ were performed for emphysema, 269 transplants (17.9\%) for cystic fibrosis, 454 transplants $(30.3 \%)$ for pulmonary fibrosis, and 68 transplants $(4.5 \%)$ for pulmonary vascular disease.

When dividing patients based on time of transplant before or after the initiation of the lung allocation score, there were mild shifts in demographics. Before the adoption of the lung allocation score (group 1), 792 patients were transplanted. The average age was $48 \pm 13$ years; 404 transplant recipients $(51 \%)$ were male and 388 transplant recipients $(49 \%)$ were female. We performed bilateral lung transplants in 615 patients $(77.7 \%)$ and single lung transplants in 177 patients $(22.3 \%)$. A total of 412 transplants (52\%) were performed for emphysema, 144 transplants $(18.2 \%)$ were performed for cystic fibrosis, 128 transplants $(16.1 \%)$ were performed for pulmonary fibrosis, and 57 transplants (7.2\%) were performed for pulmonary vascular disease. After the institution of the lung allocation score (group 2), 708 patients underwent transplantation. The average age was $50 \pm 14$ years; 418 transplant recipients $(59 \%)$ were male, and 290 transplant recipients $(41 \%)$ were female. We performed bilateral lung transplants in 681 patients $(96.2 \%)$ and single lung transplants in 27 patients $(3.8 \%)$. A total of 183 transplants $(25.8 \%)$ were performed for emphysema, 125 transplants $(17.7 \%)$ were performed for cystic fibrosis, 326 transplants $(46 \%)$ were performed for pulmonary fibrosis, and 11 transplants $(1.6 \%)$ were performed for pulmonary vascular disease.

\section{Intraoperative Management}

Patients underwent single or bilateral lung transplantation. Over time, there has been an evolution in the intraoperative management and surgical techniques being used. All patients receive a double-lumen endotracheal tube and Swan-Ganz catheter. Inhaled nitric oxide was used for all patients. Bilateral transplants were traditionally done using a clamshell incision with sternal splitting. More recently, a sternal sparing approach has been used whenever possible. If the clinical situation demands it, we use cardiopulmonary bypass for hemodynamic support during the operation. Postoperative allograft dysfunction is managed with peripheral venovenous ECMO.

\section{Postoperative Management}

The majority of recipients received either ATGAM (Pfizer, New York, NY) or an interleukin 2-receptor antagonist as induction therapy. Patients were maintained on triple-drug immunosuppression consisting of steroids, a cell cycle inhibitor, and a calcineurin inhibitor. All patients underwent routine postoperative surveillance bronchoscopy and maintenance immunosuppression was adjusted on the basis of these findings.

\section{Statistical Analysis}

Categorical data were compared with Fisher exact or chi-square tests, and normally distributed continuous variables were compared with a 2tailed Student $t$ test. Skewed data were compared with the Wilcoxon rank-sum test. Rates for survival were calculated using the Kaplan-Meier method and log-rank analysis. Data analysis was performed using SPSS software version 11.0 (SPSS, Chicago, Ill). 
TABLE 1. Demographic composition of all patients evaluated

\begin{tabular}{ll}
\hline \multicolumn{1}{c}{ Characteristic } & \multicolumn{1}{c}{ All patients } \\
\hline Age, mean $\pm \mathrm{SD}$ & $48.9 \pm 13 \mathrm{y}$ \\
$\mathrm{Sex}$ & $55 \%$ male, $45 \%$ female \\
\hline Emphysema & $39.7 \%$ \\
Cystic fibrosis & $17.9 \%$ \\
\hline Pulmonary fibrosis & $30.3 \%$ \\
Pulmonary vascular disease & $4.5 \%$ \\
Double or single transplant & $86.4 \%$ double, $13.6 \%$ single \\
Primary graft dysfunction & $26.6 \%$ \\
\hline$S D$, Standard deviation. &
\end{tabular}

\section{RESULTS}

\section{Survival}

Overall survival for all 1500 patients was $86.2 \%$ at 1 year, $73.2 \%$ at 3 years, $61.6 \%$ at 5 years, $43.2 \%$ at 10 years, and $34.5 \%$ at 15 years (Figure 1). There was a statistically significant survival difference among all disease processes (Figure 2). Chronic obstructive pulmonary disease (COPD) survival was $88.4 \%, 74.6 \%$, and $60.8 \%$ at 1,3 , and 5 years, respectively. Cystic fibrosis survival was $86.4 \%, 70.7 \%$, and $60.7 \%$ at 1,3 , and 5 years, respectively. Interstitial pulmonary fibrosis (IPF) survival was $87.7 \% \%$, $77.2 \%$, and $66.5 \%$ at 1,3 , and 5 years, respectively. Bilateral lung transplantation was associated with better survival than single lung transplant at all time points examined.

Thirty-five patients $(4.4 \%)$ in group 1 died during their index hospitalization following lung transplantation. There was a general trend toward decreased mortality over time. Overall survival was $84.3 \%, 70.7 \%$, and $56.8 \%$, at 1,3 , and 5 years, respectively.

Twenty-five patients (3.5\%) in group 2 died during their index hospitalization following lung transplantation. There was a general trend toward decreased mortality over time. Overall survival was $88.5 \%, 76.7 \%$, and $68.3 \%$, at 1,3 , and 5 years, respectively. There was a statistically significant improvement in survival between groups 1 and $2(P<.0001$; Figure 3$)$.

When one compares survival between groups by disease process, all patients regardless of disease did better in group 2 (Figure 4). Survival for COPD in group 1 was $88.5 \%$, $74.9 \%$, and $59.9 \%$ at 1,3 , and 5 years, respectively. Survival for COPD in group 2 was $88.1 \%, 74.3 \%$, and $63.7 \%$ at 1,3 , and 5 years, respectively. Survival for cystic fibrosis in group 1 was $84.7 \%, 69.3 \%$, and $56.2 \%$ at 1,3 , and 5 years, respectively. Survival for cystic fibrosis in group 2 was $88.5 \%, 72.3 \%$, and $68.2 \%$ at 1,3 , and 5 years, respectively. Survival for IPF in group 1 was $78.5 \%$, $64.5 \%$, and $51.6 \%$ at 1,3 , and 5 years, respectively. Survival for IPF in group 2 was $90.9 \%, 82.0 \%$, and $72.8 \%$ at 1,3 , and 5 years, respectively.

\section{Primary Graft Dysfunction}

Primary graft dysfunction (PGD) describes the syndrome of acute lung injury following transplantation. A recent International Society of Heart and Lung Transplantation consensus statement has revised the definition of PGD. ${ }^{4}$ PGD was measured at T0, T24, T48, and T72 hours after transplant and the presence of PGD at any point was captured. A total of 399 patients $(26.6 \%)$ had grade 3 PGD. In group 1175 patients $(22.1 \%)$ experienced grade 3 PGD while in group 2, $224(31.6 \%)$ experienced grade 3 PGD. Despite the increased incidence of PGD in the latter group, this does not appear to have affected short- and longterm survival.

\section{Bronchiolitis Obliterans Syndrome}

Freedom from BOS was $83.2 \%, 60.0 \%, 48.4 \%$, and $20.3 \%$ at $1,3,5$, and 10 years, respectively, following transplant for all patients examined (Figure 5, A). In group 1, the freedom from BOS was $83.8 \%, 55.4 \%$, and $39.4 \%$ at 1,3 , and 5 years, respectively. In group 2, the freedom from BOS was $82.5 \%, 66.3 \%$, and $61.6 \%$ at 1,3 , and 5 years

TABLE 2. Demographic composition of all patients evaluated divided in to 2 groups

\begin{tabular}{|c|c|c|c|}
\hline Characteristic & Group 1 & Group 2 & $P$ value \\
\hline Age, mean $\pm \mathrm{SD}$ & $48 \pm 13 y$ & $50 \pm 14 y$ & \\
\hline Sex & $51 \%$ male, $49 \%$ female & $59 \%$ male, $41 \%$ female & \\
\hline Emphysema & $52 \%$ & $25.8 \%$ & \\
\hline Cystic fibrosis & $18.2 \%$ & $17.7 \%$ & \\
\hline Pulmonary fibrosis & $16.1 \%$ & $46 \%$ & \\
\hline Pulmonary vascular disease & $7.2 \%$ & $1.6 \%$ & \\
\hline Double or single transplant & $77.7 \%$ double, $22.3 \%$ single & $96.2 \%$ double, $3.8 \%$ single & \\
\hline Primary graft dysfunction & $22.1 \%$ & $31.6 \%$ & $<.001$ \\
\hline Hospital mortality & $4.4 \%$ & $3.5 \%$ & $<.4$ \\
\hline 1-y survival & $84.3 \%$ & $89.3 \%$ & $<.02$ \\
\hline
\end{tabular}

Group 1 (before introduction of lung allocation score); Group 2 (after introduction of lung allocation score). Primary graft dysfunction (PGD) is defined as PGD grade 3 identified from the time of transplant to 72 hours post-transplant. $S D$, Standard deviation. 


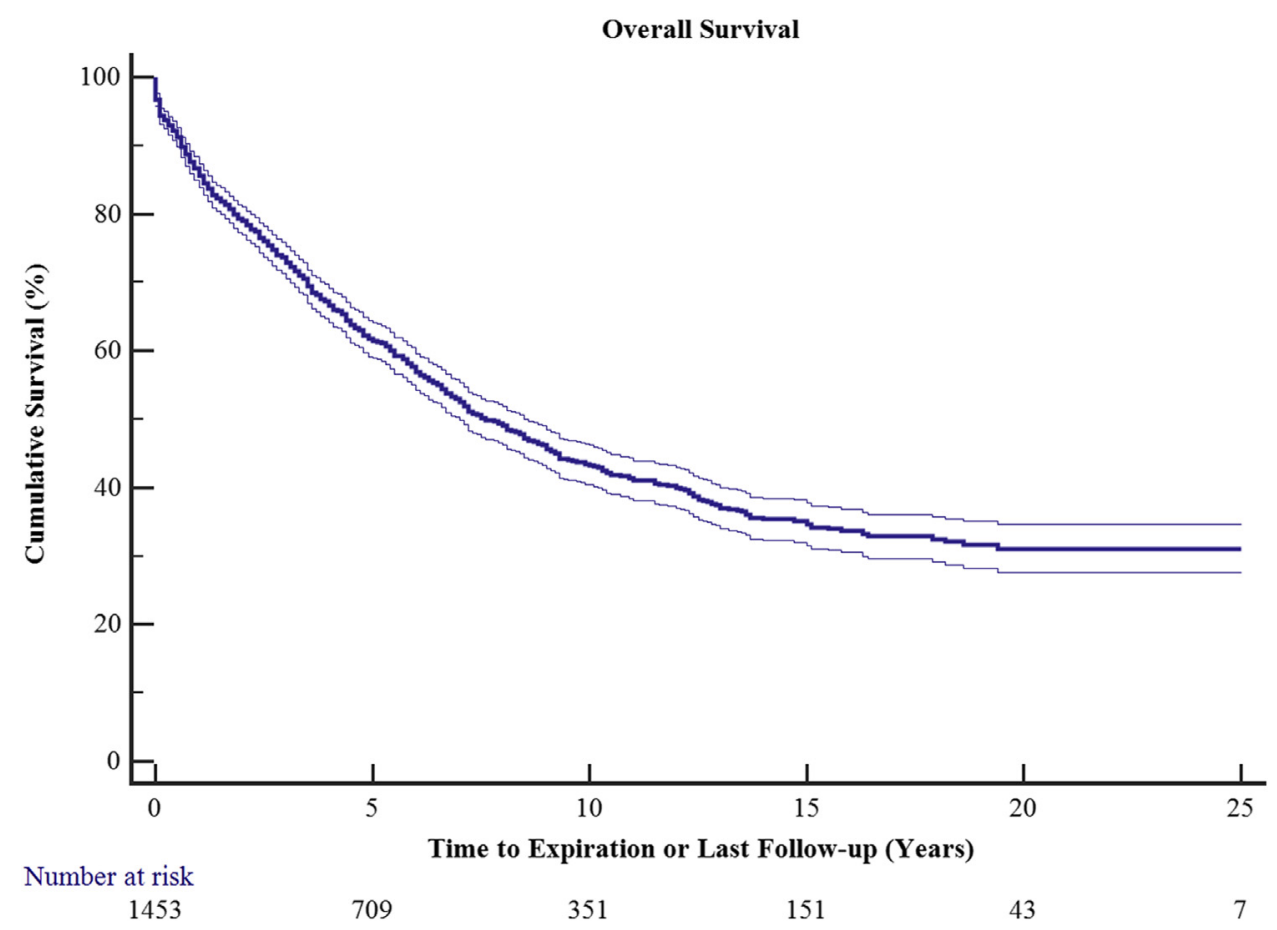

FIGURE 1. Overall survival of all 1500 transplanted patients as a function of time. Ninety-five percent confidence limits are represented by the thin lines.

respectively $(P<.0001$; Figure $5, B)$. We looked further at freedom from BOS between each group for each individual disease process; this further substantiated what was seen for the groups in aggregate. For each disease process, freedom from BOS was greater in group 2 than in group 1 (Figures E1-E3).

Although BOS has historically been used as a synonym for chronic rejection, increasing evidence suggests that BOS is the result of both alloimmune and non-alloimmune mechanisms. More recently, chronic lung allograft dysfunction has been introduced as a term to describe the heterogeneous chronic conditions following lung transplantation. Moreover, a distinction between obstructive (ie, BOS) versus restrictive (ie, restrictive allograft syndrome) physiology has been identified. ${ }^{5}$ A subset analysis of our larger group was performed. For all patients who demonstrated evidence of chronic dysfunction, $95 \%$ had obstructive physiology, whereas only $5 \%$ had restrictive physiology. For patients who underwent retransplantation, all had obstructive physiology as the reason for their initial graft failure.

\section{Length of Stay}

The median length of mechanical ventilation at 2 days, and the median length of stay in the ICU at 3 days, was not different between groups. The mean length of stay in the hospital was $21.8 \pm 1.5$ days for group 1 and $22.3 \pm 4$ days for group 2 . There was no statistical difference between groups.

\section{Donor Characteristics}

An evaluation of limited donor characteristics between group 1 and group 2 demonstrated no discernable difference. The average age for all donors was $37 \pm 11.3$ years. There was no gender difference over time. CMV mismatch between donor and recipient was $43.3 \pm 0.48 \%$ for group 1 and $44.6 \pm 0.49 \%$ for group $2(P<.62)$.

\section{DISCUSSION}

This manuscript represents that largest single-institution series of adult lung transplants that has been reported to date. The patients underwent transplantation during a period of nearly 3 decades. Our group previously reviewed our experience with 277 pediatric and 706 adult lung recipients and more recently 1000 adult recipients. This new manuscript builds on our past work and specifically looks at the population as 2 distinct groups, before and after the implementation of the lung allocation score. The implementation of the lung allocation score has been reflected in the marked change in the composition of the recipient populations. ${ }^{6}$ Moreover, our series continues to highlight the ongoing evolution of the field as reflected by the higher utilization of donors, a shift in the representation of disease processes transplanted and the persistently high rates of PGD despite refinements in preservation solutions, intraoperative techniques, and perioperative management. ${ }^{7-9}$ Survival for all patients at $1,3,5$, and 10 years appears to be somewhat better than what has been previously 


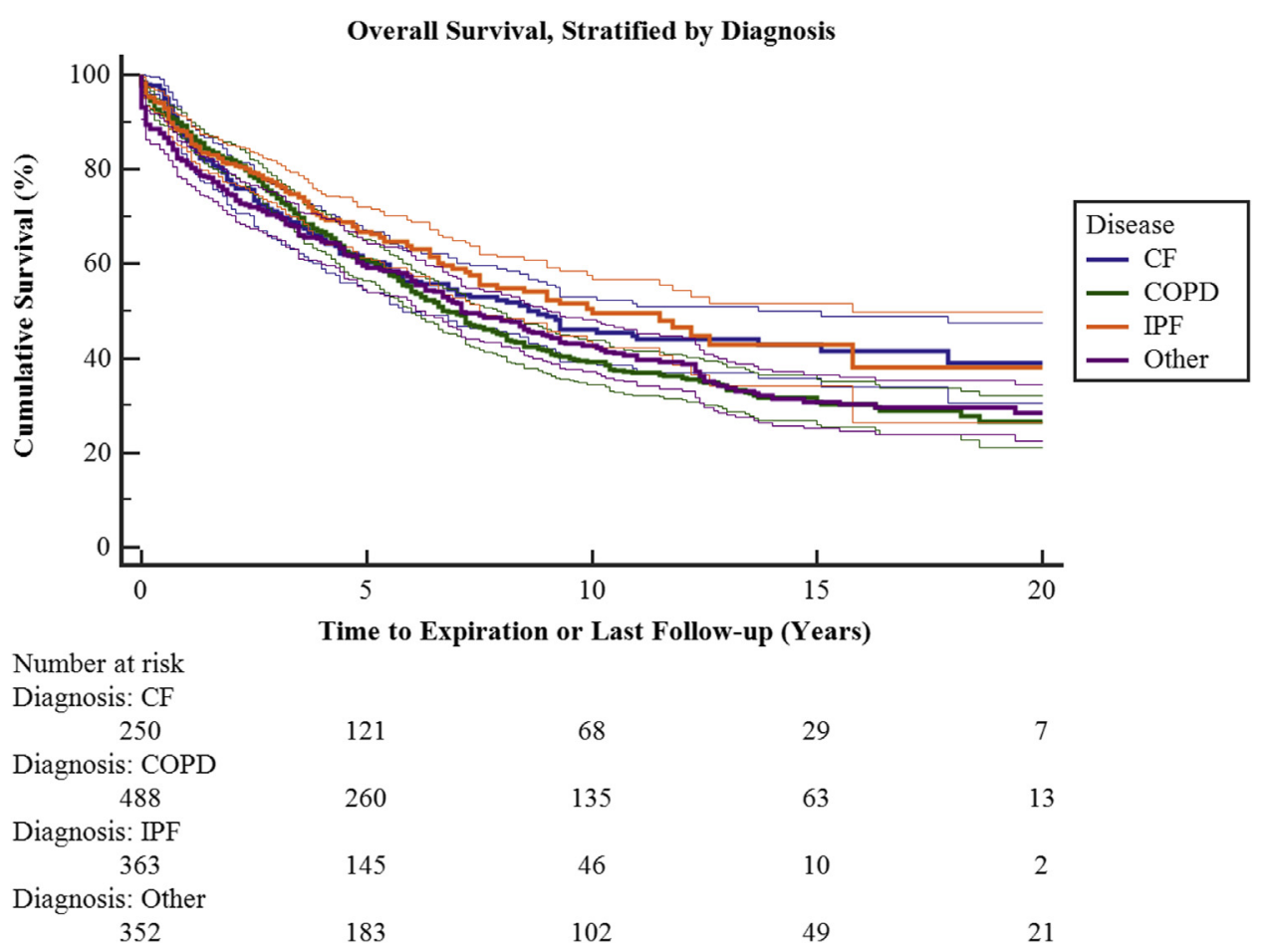

FIGURE 2. Overall survival stratified by diagnosis groups, including cystic fibrosis $(C F)$, chronic obstructive pulmonary disease $(C O P D)$, pulmonary fibrosis $(I P F)$, and other (including pulmonary hypertension, $\alpha-1$ anti-trypsin deficiency, and lymphangioleiomyomastosis). There is a statistically significant difference in survival among the groups $(P<.007)$. Ninety-five percent confidence limits are represented by the thin lines. See Table E1 for survival and $95 \%$ confidence intervals separated by disease process.

reported in the literature. In addition, it appears that survival at these time points has improved over time. Improvement in late survival is a function, in part, of improved early survival. Factors that may have contributed to improvements in early survival, and especially to decrease in hospital mortality, are refinements in perioperative management. Starting in 2000, a team of critical care physicians has been involved in the management of our lung transplant recipients during their stay in the intensive care unit. Moreover, we have created lung transplantspecific units to manage these patients once their acute postsurgical issues have been addressed. Over the course of this study, we have implemented changes to our immunosuppressive regimen, which we believe have contributed to improvements in long-term survival. This contribution is illustrated by the results of a study published from our institution suggesting that maintenance therapy with tacrolimus was superior to cyclosporine. ${ }^{10}$ During this same time span, we introduced new treatment strategies for bronchiolitis obliterans. ${ }^{11,12}$ It appears that our overall improvement in survival is multifactorial. Although improved early survival is the largest determinant of prolonged survival, we cannot discount the role of improved management of long-term complications. A review of the registry of the International Society of Heart and Lung Transplantation yielded similar conclusions. ${ }^{1,13}$
As we look to differences between the 2 groups, there has been a shift to performing almost exclusively bilateral lung transplants. Our preference is to perform bilateral rather than single-lung transplants for patients with both suppurative and nonsuppurative lung diseases. We have previously reported that bilateral lung transplantation for patients with COPD is associated with better long-term survival than single lung transplantation, a finding that has since been supported by others. ${ }^{14-18}$ The decision to perform single-lung transplants is often driven by a desire to expand the number of potential recipients. Rarely is it driven by intraoperative considerations. As advances in ex vivo reconditioning and increased comfort with expanded criteria donors continues, we would expect bilateral lung transplantation to become the norm.

One of the most striking findings was that a relatively large number of patients experienced grade 3 PGD after transplantation. PGD after lung transplantation is the clinical presentation of ischemia-reperfusion injury. Experimental and clinical studies have suggested that lungs, when compared with other solid organ transplants, experience a higher incidence of ischemia-reperfusion injury. ${ }^{19,20}$ Multiple groups have attempted to uncover the causes of PGD. There is some evidence to suggest that the type of preservation solution used might play a role. ${ }^{21-23}$ Others contend that non-COPD recipient diagnoses are a risk factor 


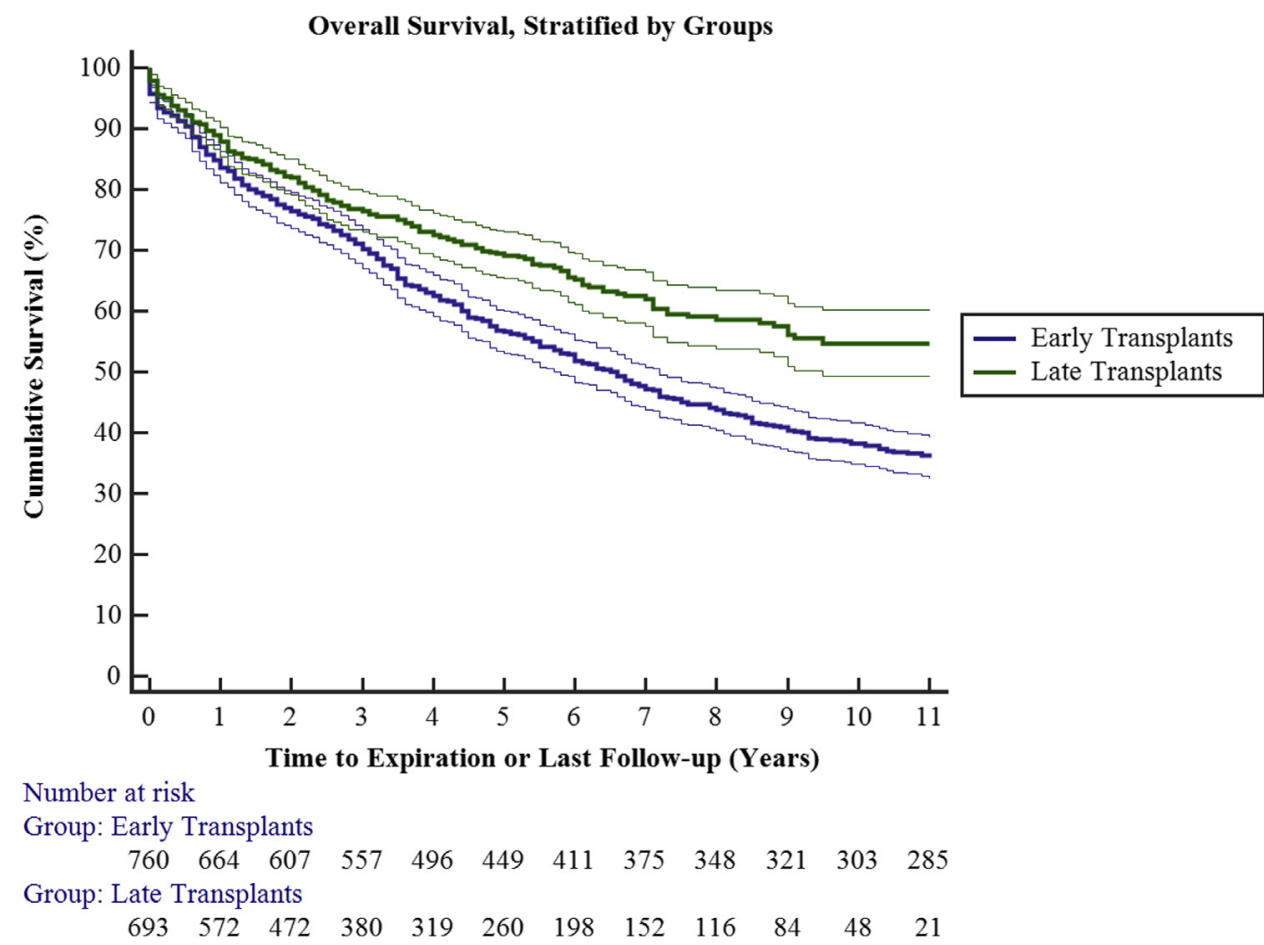

FIGURE 3. Overall survival stratified by time groups. Early transplant (group 1) had decreased short- and long-term survival when compared with late transplant (group 2; $P<.0001$ ). Ninety-five percent confidence limits are represented by the thin lines.

for the development of PGD. ${ }^{24}$ The most commonly supported argument is that the progressive shift toward marginal donors results in a higher incidence of PGD. ${ }^{25-27}$ Some have identified donor smoking history and age of the donor as risk factors for PGD. The demographic makeup of our recipients in groups 2 would support the findings of others. Group 2 had a higher incidence of PGD, an increased age of recipients, and an increased incidence of non-COPD recipients. Limited demographic data on donors would suggest no difference between groups. Interestingly, while group 2 had an overall higher incidence of grade 3 PGD, these patients had better survival at index hospitalization and at all additional time points evaluated. Nonetheless, this persistently high rate of PGD demands ongoing research to understand the drivers behind PGD and potential therapeutic strategies to minimize its occurrence. It also suggests that we should refine the manner in which PGD is diagnosed. $\mathrm{PaO}_{2} / \mathrm{FiO}_{2}$ ratios can be calculated, but they provide limited information on the function of the allograft. Moreover, chest radiograph interpretation is subject to some variability. It is possible that a more rigorous approach should be taken to define PGD.

Interestingly, although the incidence of PGD was greater in group 2, the incidence of BOS in that same group was significantly lower than in group 1 . This finding is unique and different from what we and other centers have previously reported. Although PGD is an acute, perioperative presentation of ischemia reperfusion injury, BOS is the clinical presentation of chronic rejection. It has long been postulated that the presence of PGD following transplant reduces graft and patient survival; however, our findings suggest that is not always the case. The finding that group 2 had a higher incidence of PGD compared with group 1, but still had improved survival and freedom from bronchiolitis obliterans, is intriguing. This finding suggests that the drivers of both short- and long-term survival are a variety of factors that act in concert and are still not fully understood.

The increasing number of patients dying on the waiting list, largely because of the paucity of donor organs, was the principle driver behind the introduction of the lung allocation score. The Lung Allocation Score, devised to prioritize candidates awaiting lung transplantation, is calculated using the predicted duration of survival on the wait list while also considering the recipient's likelihood of posttransplant survival. ${ }^{28-31}$ This score is generated, in part, on the severity of the candidate's comorbid illnesses. The actual relationship between the LAS and survival is unknown, but recent studies suggest that patients with high LAS scores do reasonably well following transplant. ${ }^{32}$ The use of the LAS has resulted in a shift toward transplants more fibrotic patients and fewer COPD patients. These findings are supported by our data. Moreover, it appears that transplanting sicker patients has not resulted in worse outcomes. 


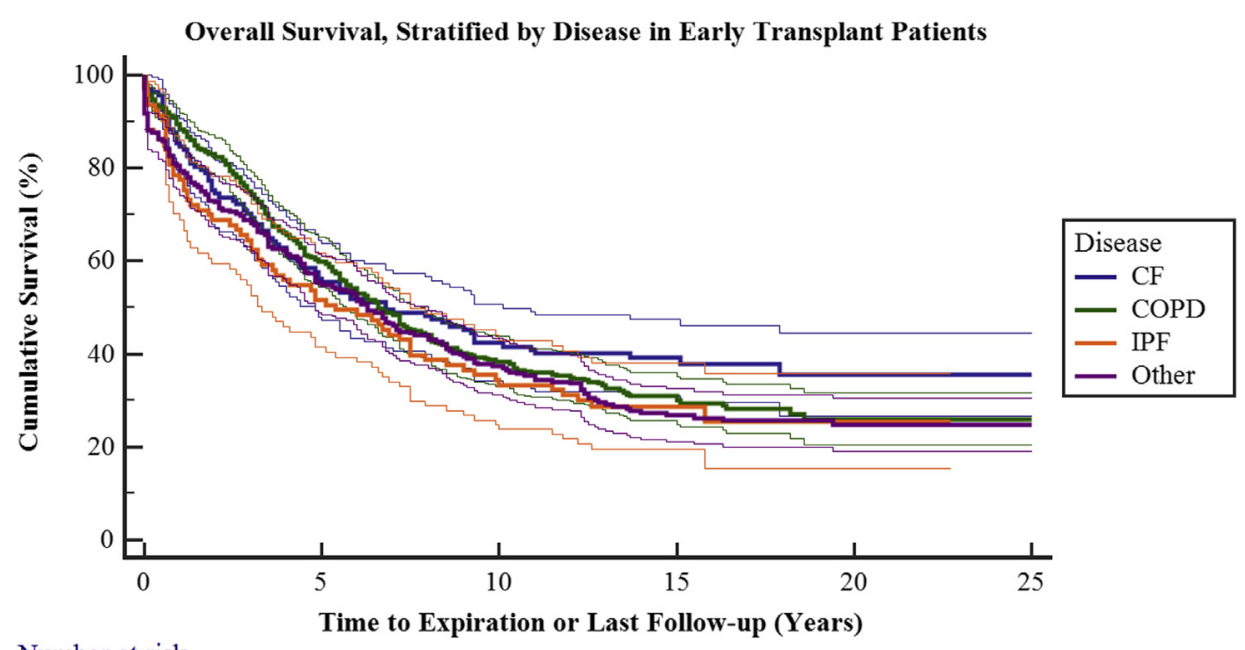

Number at risk
Diagnosis: CF

\begin{tabular}{|c|c|c|c|c|c|}
\hline \multirow{2}{*}{\multicolumn{6}{|c|}{$\begin{array}{c}133 \\
\text { Diagnosis: COPD }\end{array}$}} \\
\hline & & & & & \\
\hline 315 & 193 & 124 & 63 & 13 & 3 \\
\hline \multicolumn{5}{|c|}{ Diagnosis: IPF } & \\
\hline 91 & 48 & 31 & 10 & 2 & \\
\hline \multicolumn{5}{|c|}{ Diagnosis: Other } & \\
\hline 221 & 132 & 90 & 49 & 21 & \\
\hline
\end{tabular}

A

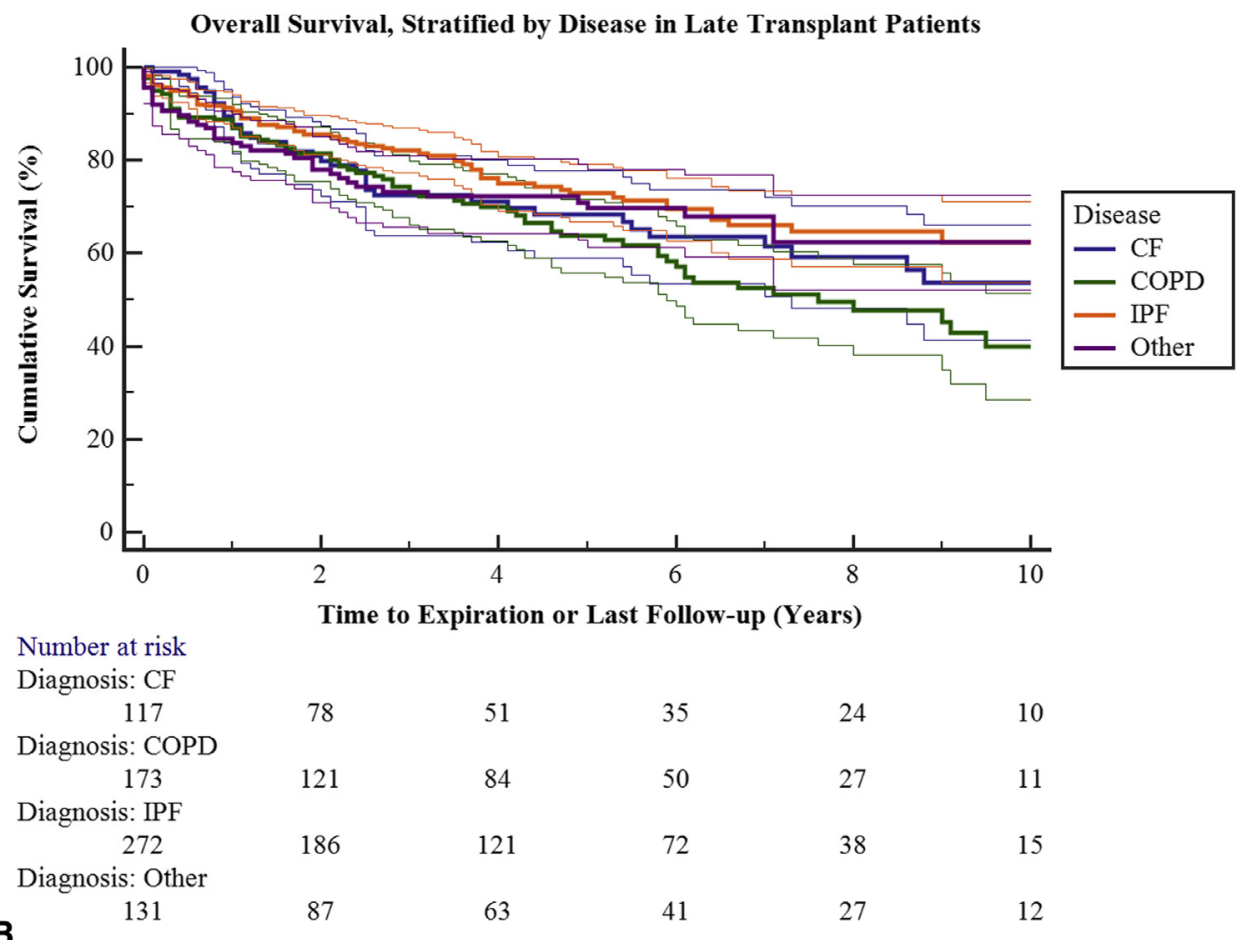

FIGURE 4. A, Overall survival stratified by diagnosis groups in early transplant patients. Ninety-five percent confidence limits are represented by the thin lines. See Table E2 for survival and $95 \%$ confidence intervals separated by disease process. B, Overall survival stratified by diagnosis groups in late transplant patients. Ninety-five percent $95 \%$ confidence limits are represented by the thin lines. See Table E3 for survival and $95 \%$ confidence intervals separated by disease process. $C F$, Cystic fibrosis; $C O P D$, chronic obstructive pulmonary disease; $I P F$, interstitial pulmonary fibrosis. 


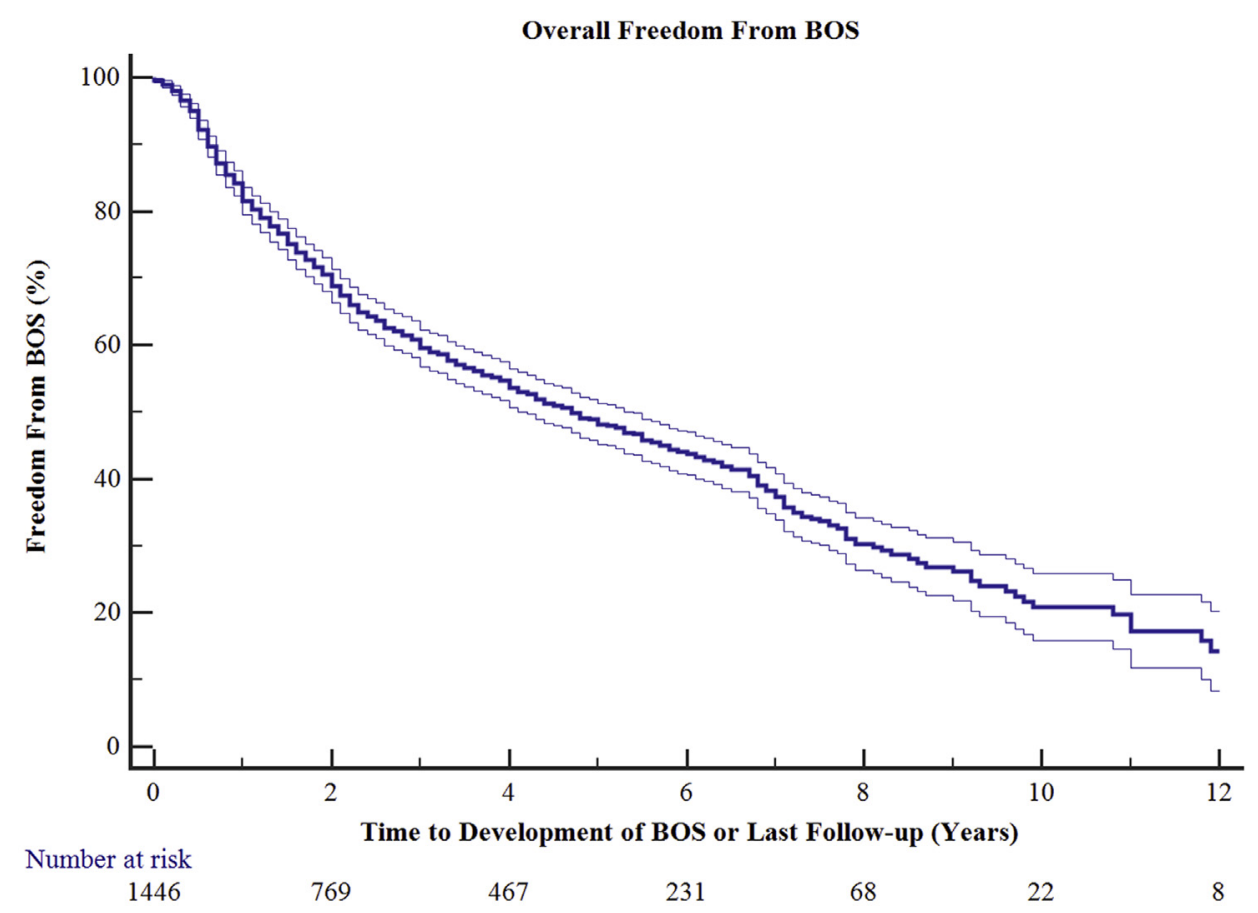

A

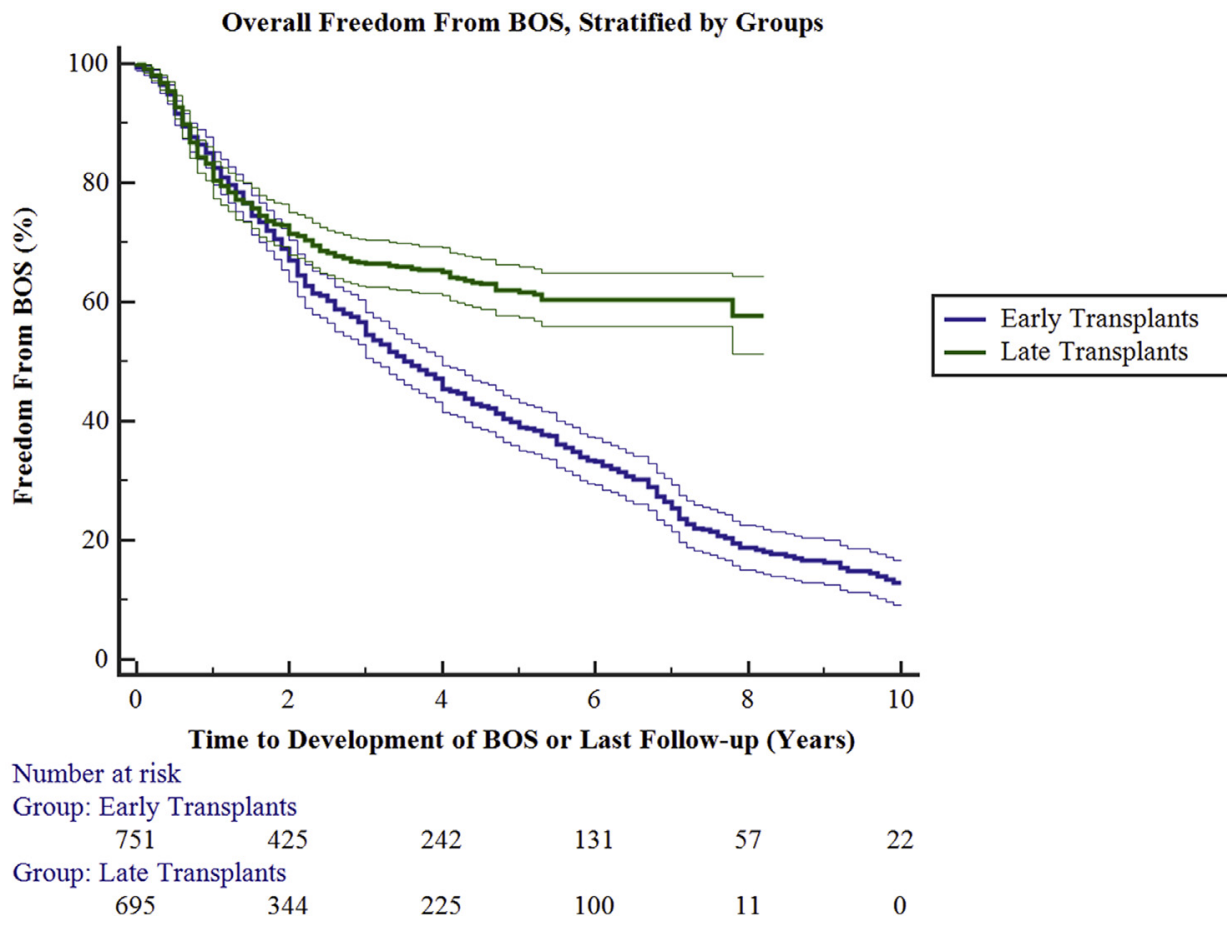

B

FIGURE 5. A, Overall time to development of bronchiolitis obliterans syndrome (BOS). Ninety-five percent confidence limits are represented by the thin lines. B, Overall time to development of BOS, stratified by time groups. Early transplant (group 1) had a statistically significant reduced freedom from BOS at all time points compared to late transplant (group $2 ; P<.0001$ ). Ninety-five percent confidence limits are represented by the thin lines. 


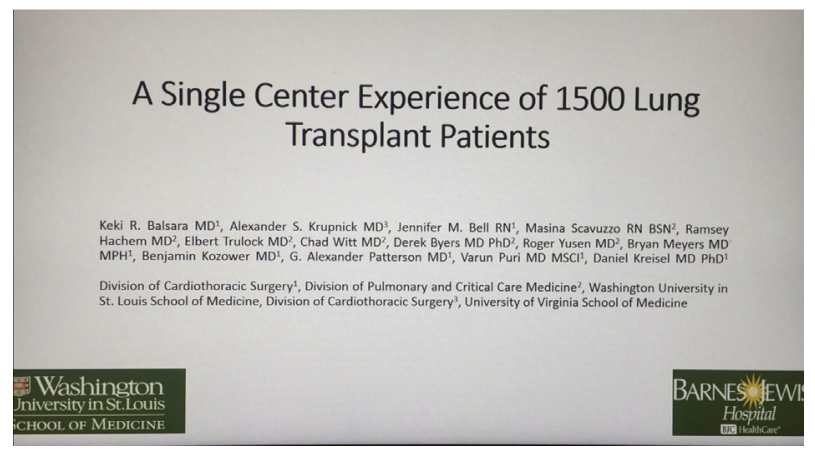

VIDEO 1. Video recording highlighting the most salient features of this manuscript using slides from The American Association for Thoracic Surgery 2017 oral presentation. Information highlighted includes overall survival, disease-specific survival, and incidence of primary graft dysfunction and bronchiolitis obliterans syndrome across all groups examined. Video available at: https://www.jtcvs.org/article/S0022-5223(18)30894-8/fulltext.

\section{CONCLUSIONS}

Our program has evolved along with the field of lung transplantation. Over 3 decades, we have changed our perioperative management of patients, expanded the pool of possible donors and recipients, and witnessed a shift toward transplants in sicker patients because of the introduction of the LAS. Although we have enjoyed superior results, many challenges remain in the field of lung transplantation. The prospect of reconditioning marginal lungs is on the forefront of exciting developments. It also creates the possibility of novel therapeutic interventions before resorting to transplantation. We have historically believed that the treatment and prevention of PGD would have the greatest influence on long-term allograft survival. Our findings suggest that although PGD might have a role in long-term allograft failure, there are potentially other factors at play. These factors include alterations in immunosuppression, the use of a multidisciplinary team, earlier identification and treatment of infections, and improved surveillance for donor-specific antibodies and antibody mediated rejection. A combination of clinical outcomes and basic science research will be necessary to elucidate this matter more fully (Video 1).

\section{Webcast}

You can watch a Webcast of this AATS meeting presentation by going to: https://aats.blob.core.windows.net/ media/17AM/2017-05-02/RM302-304/05-02-17_Room302304_1555_Balsara.mp4.

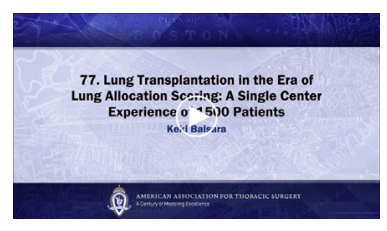

\section{Conflict of Interest Statement}

Authors have nothing to disclose with regard to commercial support.

\section{References}

1. Yusen RD, Edwards LB, Dipchand AI, Goldfarb SB, Kucheryavaya AY, Levvy BJ, et al. The registry of the International Society for Heart and Lung Transplantation: thirty-third adult lung and heart-lung transplant report-2016; Focus theme: primary diagnostic indications for transplant. J Heart Lung Transplant. 2016;35:1170-84.

2. Meyers BF, de la Morena M, Sweet SC, Trulock EP, Guthrie TJ, Mendeloff EN, et al. Primary graft dysfunction and other selected complications of lung transplantation: a single-center experience of 983 patients. J Thorac Cardiovasc Surg. 2005;129:1421-9.

3. Kreisel D, Krupnick AS, Puri V, Guthrie TJ, Trulock EP, Meyers BF, Patterson GA. Short- and long-term outcomes of 1000 adult lung transplant recipients at a single center. J Thorac Cardiovasc Surg. 2011;141: 215-22.

4. Snell GI, Yusen RD, Weill D, Strueber M, Garrity E, Reed A, et al. Report of the ISHLT working group on primary lung graft dysfunction, part I: definition and grading-A 2016 consensus group statement of the International Society for Heart and Lung Transplantation. J Heart Lung Transplant. 2017;36:1097-103.

5. Gauthier JM, Hachem RR, Kreisel D. Update on chronic lung allograft dysfunction. Curr Transplant Rep. 2016;3:185-91.

6. Vock DM, Durheim MT, Tsuang WM, Finlen Copeland CA, Tsiatis AA, Davidian M, et al. Survival benefit of lung transplantation in the modern era of lung allocation. Ann Am Thorac Soc. 2017;14:172-81.

7. Russo MJ, Worku B, Iribarne A, Hong KN, Yang JA, Vigneswaran W, Sonett JR Does lung allocation score maximize survival benefit from lung transplantation? J Thorac Cardiovasc Surg. 2011;141:1270-7.

8. Schaffer JM, Singh SK, Joyce DL, Reitz BA, Robbins RC, Zarmanian RT, Mallidi HR. Transplantation for idiopathic pulmonary arterial hypertension: improvement in the lung allocation score era. Circulation. 2013;127:2503-13.

9. Gall H, Felix JF, Schneck FK, Milger K, Sommer N, Voswinckel R, et al. The Giessen pulmonary hypertension registry: survival in pulmonary hypertension subgroups. J Heart Lung Transplant. 2017;36:957-67.

10. Hachem RR, Yusen RD, Chakinala MM, Meyers BF, Lynch JP, Aloush AA, et al. A randomized controlled trial of tacrolimus versus cyclosporine after lung transplantation. J Heart Lung Transplant. 2007;26:1012-8.

11. Jain R, Hachem RR, Morrell MR, Trulock EP, Chakinala MM, Yusen RD, et al. Azithromycin is associated with increased survival in lung transplant recipients with bronchiolitis obliterans syndrome. J Heart Lung Transplant. 2010;29:531-7.

12. Morrell MR, Despotis GJ, Lublin DM, Patterson GA, Trulock EP, Hachem RR. The efficacy of photopheresis for bronchiolitis obliterans syndrome after lung transplantation. J Heart Lung Transplant. 2010;29:424-31.

13. Christie JD, Edwards LB, Kucheryavaya AY, Benden C, Dipchand AI, Dobbels F, et al. The registry of the International Society for Heart and Lung Transplantation: twenty-sixth official adult lung and heart-lung transplantation report2009. J Heart Lung Transplant. 2009;28:1031-49.

14. Cassivi SD, Meyers BF, Battafarano RJ, Guthrie TJ, Trulock EP, Lynch JP, et al. Thirteen-year experience in lung transplantation for emphysema. Ann Thorac Surg. 2002; 74:1663-9; discussion 1669-70.

15. Thabut G, Christie JD, Ravaud P, Castier Y, Brugiere O, Fournier M, et al. Survival after bilateral versus single lung transplantation for patients with chronic obstructive pulmonary disease: a retrospective analysis of registry data. Lancet. 2008;371:744-51.

16. Hadjiliadis D, Chaparro C, Gutierrez C, Steele MP, Singer LG, Davis RD, et al. Impact of lung transplant operation on bronchiolitis obliterans syndrome in patients with chronic obstructive pulmonary disease. Am J Transplant. 2006;6: 183-9.

17. Nwakanma LU, Simpkins CE, Williams JA, Chang DC, Borja MC, Conte JV, Shah AS. Impact of bilateral versus single lung transplantation on survival in recipients 60 years of age and older: analysis of United Network for Organ Sharing database. J Thorac Cardiovasc Surg. 2007;133:541-7.

18. Pochettino A, Kotloff RM, Rosengard BR, Arcasoy SM, Blumenthal NP, Kaiser LR, Bavaria JE. Bilateral versus single lung transplantation for chronic 
obstructive pulmonary disease: intermediate-term results. Ann Thorac Surg. 2000;70:1813-8; discussion 1818-9.

19. Shaver CM, Ware LB. Primary graft dysfunction: pathophysiology to guide new preventive therapies. Expert Rev Respir Med. 2017;11:119-28.

20. Diamond JM, Cantu E, Porteous MK, Suzuki Y, Meyer KC, Lederer DJ, et al. Peripheral blood gene expression changes associated with primary graft dysfunction after lung transplantation. Am J Transplant. 2017;17:1770-7.

21. Fischer S, Matte-Martyn A, De Perrot M, Waddell TK, Sekine Y, Hutcheon M, Keshavjee S, et al. Low-potassium dextran preservation solution improves lung function after human lung transplantation. J Thorac Cardiovasc Surg. 2001; 121:594-6.

22. Nath DS, Walter AR, Johnson AC, Radosevich DM, Prekker ME, Herrington CS, et al. Does Perfadex affect outcomes in clinical lung transplantation? J Heart Lung Transplant. 2005;24:2243-8.

23. Wittwer T, Albes JM, Fehrenbach A, Pech T, Franke UF, Richter J, Wahlers T. Experimental lung preservation with Perfadex: effect of the NO-donor nitroglycerin on postischemic outcome. J Thorac Cardiovasc Surg. 2003;125:1208-16.

24. Whitson BA, Nath DS, Johnson AC, Walker AR, Prekker ME, Radosevich DM, et al. Risk factors for primary graft dysfunction after lung transplantation. $J$ Thorac Cardiovasc Surg. 2006;131:73-80.

25. Geube MA, Perez-Protto SE, McGrath TL, Yang D, Sessler DI, Budev MM, et al. Increased intraoperative fluid administration is associated with severe primary graft dysfunction after lung transplantation. Anesth Analg. 2016;122:1081-8.

26. Diamond JM. Predicting primary graft dysfunction after lung transplantation: trying to catch it early. Transplantation. 2017;101:21-2.

27. Hashimoto K, Cypel M, Kim H, Machuca TN, Nakajima D, Chen M, et al. Soluble adhesion molecules during ex vivo lung perfusion are associated with posttransplant primary graft dysfunction. Am J Transplant. 2016;17: 1396-404.

28. Kozower BD, Meyers BF, Smith MA, De Oliveira NC, Cassivi SD, Guthrie TJ, et al. The impact of the lung allocation score on short-term transplantation outcomes: a multicenter study. J Thorac Cardiovasc Surg. 2008;135:166-71.

29. Davis SQ, Garrity ER Jr. Organ allocation in lung transplant. Chest. 2007;132: 1646-51.

30. Egan TM, Kotloff RM. Pro/Con debate: lung allocation should be based on medical urgency and transplant survival and not on waiting time. Chest. 2005;128: 407-15.

31. Egan TM, Murray S, Bustami RT, Shearon TH, McCullough KP, Edwards LB, et al. Development of the new lung allocation system in the United States. Am J Transplant. 2006;6(5 Pt 2):1212-27.

32. Crawford TC, Grimm JC, Magruder JT, Ha J, Sciortino CM, Kim BS, et al. Lung transplant mortality is improving in recipients with a lung allocation score in the upper quartile. Ann Thorac Surg. 2017;103:1607-13.

Key Words: lung transplantation, primary graft dysfunction, bronchiolitis obliterans, lung allocation score, emphysema, cystic fibrosis, pulmonary fibrosis, chronic rejection

\section{Discussion}

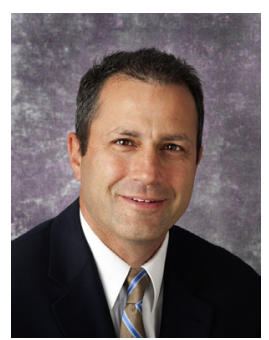

Dr Jonathan D'Cunha (Pittsburgh, $P a)$. I want to thank the AATS for the opportunity to discuss this paper, and I want to thank the authors for sending the manuscript in advance.

The Wash U group should be congratulated on their single-institution report of 1500 patients undergoing lung transplantation that compares outcomes in the pre- to post-LAS era. The increasing number of patients dying on the waiting list largely due to a paucity of donor organs was the principal driver behind the introduction of the LAS system in 2005. The LAS score was devised to prioritize candidates awaiting lung transplantation. It was calculated using a predicted duration of survival on the wait list while also taking into consideration the recipient's likelihood of posttransplant survival at 1 year. The utilization of the score has resulted in a shift towards transplanting more fibrotic patients and fewer COPD patients. The actual relationship between LAS and survival is unknown, but recent studies suggest that patients with high LAS scores do reasonably well following transplant, and the choice to transplant sicker patients has not resulted in worse outcomes. The authors have provided important data which demonstrate a higher rate of PGD in the current LAS era, an impression that we as lung transplant surgeons sometimes have felt.

I have 6 questions regarding your work; they are pretty straightforward, and I will ask them serially and await your response. Number one, I think the most intriguing observation you commented on was the higher rate of PGD in group 2. How can you explain the improved survival in this post-LAS group despite the increased rates of PGD? Any theories?

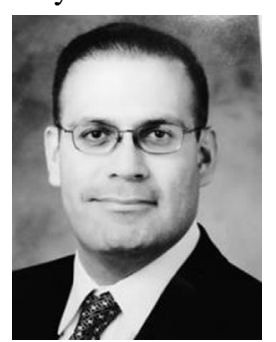

Dr Keki Balsara (St. Louis, Mo). That is a very good question. Historically we have often believed that PGD early on is the best indicator of long-term graft failure. I think what this perhaps suggests is that the cause of long-term graft failure might be multifactorial, and that while PGD plays a factor, other things, such as the appropriate treatment of infection, the more ready recognition of antibody-mediated rejection, do play roles. I think moreover, as you saw from the demographics, we have shifted towards performing more doublelung transplants than single-lung transplants, and that in and of itself is a predictor of improved survival.

Dr D'Cunha. With regards to your patient demographics, in your manuscript you didn't comment on the pediatric exclusion. I noticed in the talk here you did. I guess my question in follow-up to that is also, what was the age range of the patients in the study? Where was the pediatric cutoff?

Dr Balsara. Eighteen.

Dr D'Cunha. Did you include retransplants in the analysis? I would think this patient population would be part of the exclusion criteria for all of our outcomes pre- and postLAS, but I was just curious if you included those.

Dr Balsara. For the purpose of this study, we actually did include retransplants.

Dr D'Cunha. It is my feeling one of the major factors which affects outcomes in lung transplantation is the variability in the donor organ. I realize you were somewhat limited in your ability to pull some of those donor organ data. This can occur because of numerous variables, not the least of which is I think the procurement 
process. I was recently at a PI meeting for the EVLP trials. In 7 different centers, we noted procured organs 7 different ways. Although some of the nuances to the differences are subtle, I truly believe that we as a field should be setting a standard process for procurement and graft protection such that we can work towards analyzing outcomes with relationship to standards in donor procurement.

I was curious, because you do have a potential for an era effect here in this, did you notice any change in overall procurement process or graft protection, or do you have the same standard practice for donor procurement for the past 20 or so years?

Dr Balsara. Certainly over the past decade the manner in which procurement has occurred has been relatively uniform, and in fact there have been minimal variations in the procurement process over the duration of this study.

Dr D'Cunha. You and the coauthors have presented the difference in raw BOS rate by era. I think it is very intriguing. It does not appear that you have adjusted for any of the covariates that are strongly associated with BOS, such as rejection events, et cetera. Have you thought about including these in your manuscript to give further depth to the analysis?

Dr Balsara. Yes. We are actually in the midst of amassing that data and including that as part of the analysis.

Dr D'Cunha. And then my final question-it's more maybe theoretical or looking to your thoughts to the future, but given your findings, what might you predict regarding the future rate of PGD in the EVLP era, especially as we push the envelope in some of the trials that are going on with more marginal donors? Would you predict that our PGD rate might actually continue to increase, or do you think that we are going to have additional strategies which might mitigate that?

Dr Balsara. I suspect it will be the latter. I think in many respects lung reconditioning is sort of the most exciting thing on the forefront of lung transplantation, and if we are able to more readily identify those donor organs that are ultimately of better quality at the time of transplant, I suspect that we should see a decrease in PGD over the long term.

Dr D'Cunha. Thank you. Congratulations again.

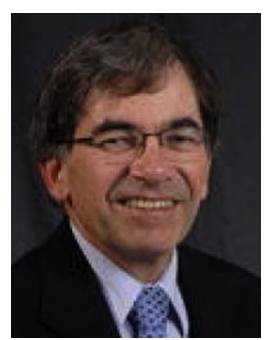

Dr Thomas M. Egan (Chapel Hill, $N C$ ). I want to congratulate you on presenting really very good results, particularly in the second cohort. I just want to point out that so many other things have changed. The lung allocation score system changed who was more likely to be offered a graft, but your improved survival may be due to a lot of factors, including changing personnel. I suspect Dr Kreisel was probably in grade school when the Wash U program started, and now he is directing the program. So there has been a huge amount of change and standardization of postoperative care that really wasn't part of the first cohort.

The other thing you mentioned was we are doing older patients, and I think that's not so much because of the LAS but rather that trend was starting before the lung allocation score came into effect and it is just reflecting the change in practice, and I wondered if you could comment on how much change in personnel and practice and care contributed to the improved survival.

Dr Balsara. That is a very important point, because I do think lung transplantation, to a large degree, is a team-oriented endeavor. So certainly what we have seen at Wash $\mathrm{U}$, and I think one of the biggest determinants of improved survival, has been the fact that now for about 16 years we have had a multidisciplinary critical care and pulmonary medicine team that really follows these patients from the time they exit the operating room until their time of discharge, and that perhaps more than anything else has contributed to improved survival.

Regarding the operative personnel, we have been blessed with the fact that our program was started by Drs Cooper and Patterson.

Dr Patterson still does lung transplants, and he has trained and mentored every other surgeon in our group who does that operation, and so we have actually enjoyed tremendous stability and consistency of intraoperative practice as well as intraoperative personnel.

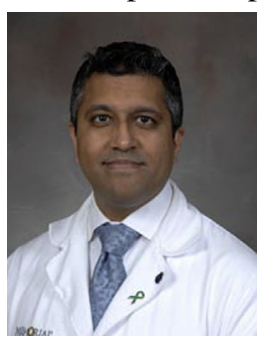

Dr Keshava Rajagopal (Houston, Tex). A very nice talk, Keki. It had been noted earlier that the LAS incentivizes high acuity lung transplantation and that in part relates to the need for extracorporeal heart and lung support both pre and intraoperatively, and I wanted to know what you observed in your patient cohort.

Dr Balsara. I'm sorry, could you say that one more time?

Dr Rajagopal. The LAS incentivizes high acuity transplantation, and so that relates in part, albeit loosely, to potentially needing extracorporeal heart and/or lung support either preoperatively or intraoperatively, and I wanted to know what you observed in your patient cohort.

Dr Balsara. I should preface this by saying at Wash U, if we need some sort of intraoperative support, we typically defer to cardiopulmonary bypass instead of ECMO. In the current era, and actually even if we look in the first group, it's approximately $25 \%$ of patients who end up needing some sort of support during the time of the operation itself that's typically due to 
hemodynamic instability or inability to tolerate singlelung ventilation.

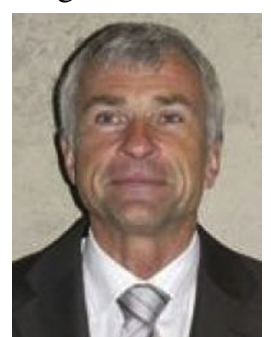

Dr Walter Klepetko (Vienna, Austria). Congratulations on this very enormous experience and congratulations to the group on driving the engine of lung transplantation forward over this long period of time.

In your data, I missed the cohort of $\mathrm{PH}$ patients that you have transplanted. I assume that they are within the "other indication" group. However, could you specifically comment on your experience with $\mathrm{PH}$ patients and whether you observed any differences in survival between the two periods of time?

Dr Balsara. In truth, I didn't look specifically at the pulmonary hypertensive patients between the 2 groups given the fact that in the first group the total percent was approximately $8 \%$, but in group 2 after the introduction of LAS it was only approximately $1 \%$, and therefore we didn't feel that there were enough patients to really make that analysis worthwhile.

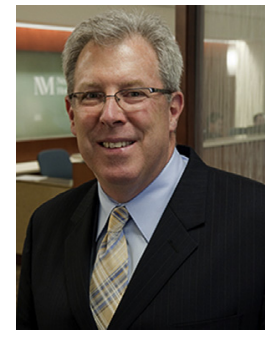

Dr Malcolm M. DeCamp (Chicago, Ill). I really enjoyed that. It's remarkable in the second group I think you said that 96 plus percent had bilateral transplants. What do you do when someone just offers you one lung? Do you pass on those? Is there ever someone you would do a single-lung transplant on?

Dr Balsara. I do think there are certain instances when we have done single-lung transplant. Sometimes those are driven by intraoperative decision making, but I think as a program we have typically gone to listing and then proceeding with bilateral lung transplants in virtually all of our patients.

Dr DeCamp. So for your older cohort where the overall survival issues may be a little more murky, do you still prefer bilateral if you have a 70-plus year old COPD patient?

Dr Balsara. Yes, that has been our practice. I think it is driven in large part due to the improved long-term survival of bilateral versus single transplant. 


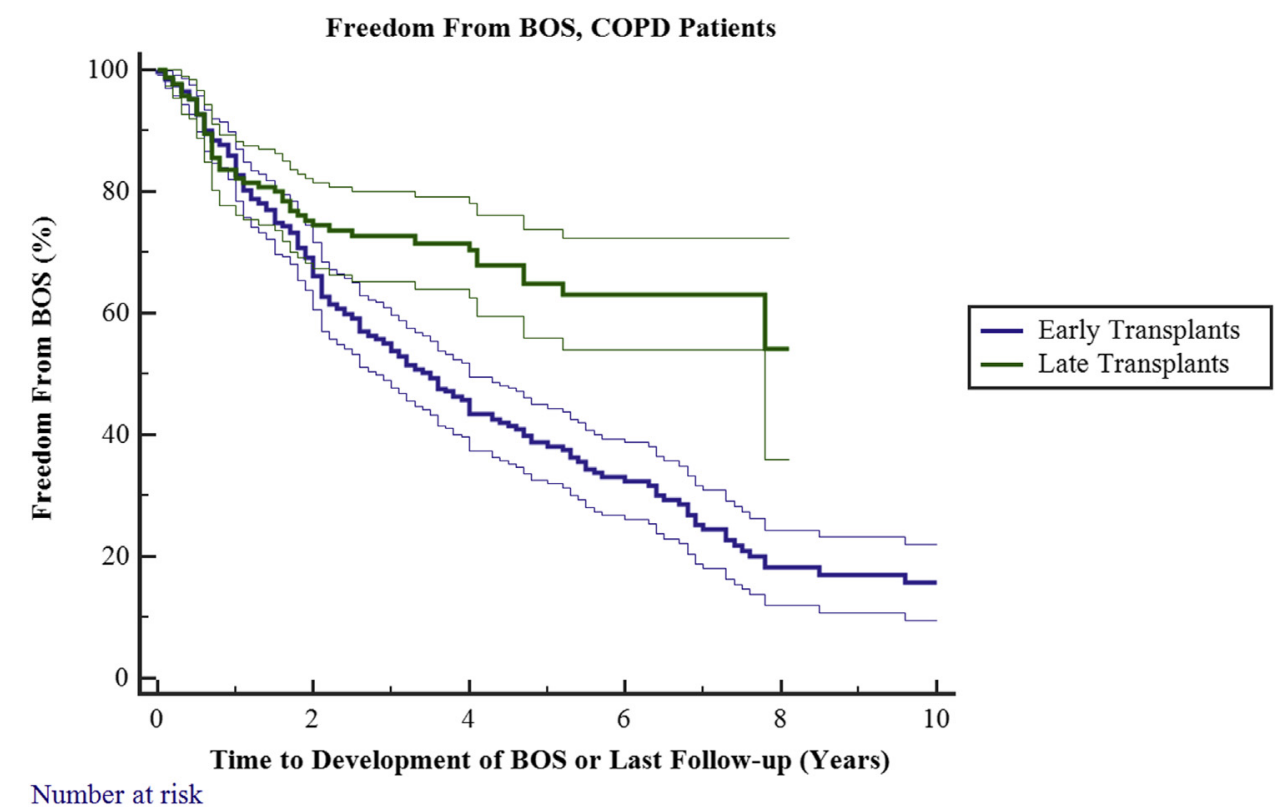

Number at risk

Group: Early Transplants

$$
312 \quad 172
$$

Group: Late Transplants

172

87

$90 \quad 44$

55
44

25

$\begin{array}{ll}19 & 9 \\ 2 & 0\end{array}$

FIGURE E1. Freedom from bronchiolitis obliterans syndrome $(B O S)$ for patients with chronic obstructive pulmonary disease, separated by group. Early transplant (pre-las) and late transplant (post-las) $95 \%$ confidence limits are represented by the thin lines. COPD, Chronic obstructive pulmonary disease.

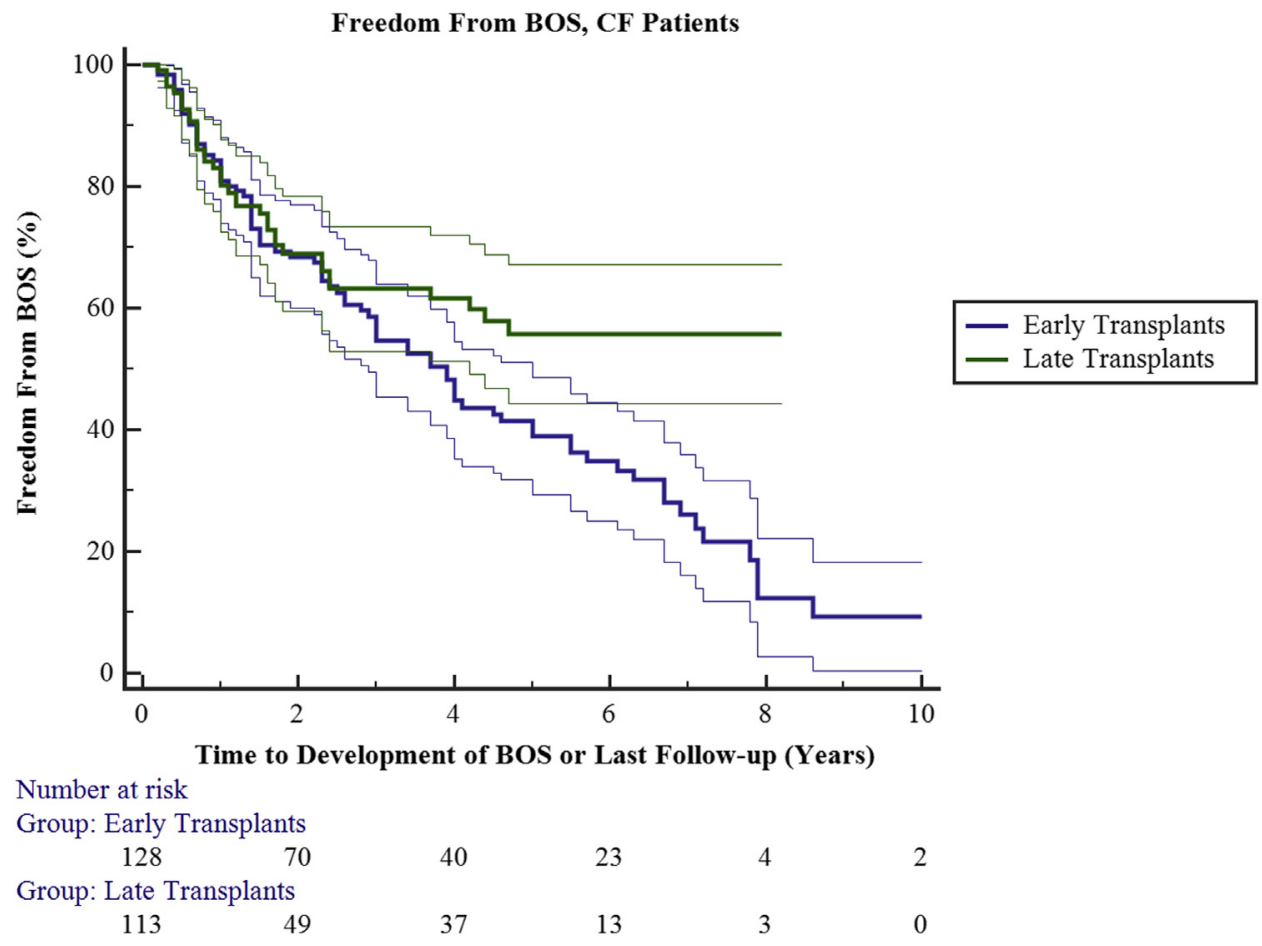

FIGURE E2. Freedom from bronchiolitis obliterans syndrome (BOS) for patients with cystic fibrosis, separated by group. Early transplant (pre-las) and late transplant (post-las) $95 \%$ confidence limits are represented by the thin lines. $C F$, Cystic fibrosis. 


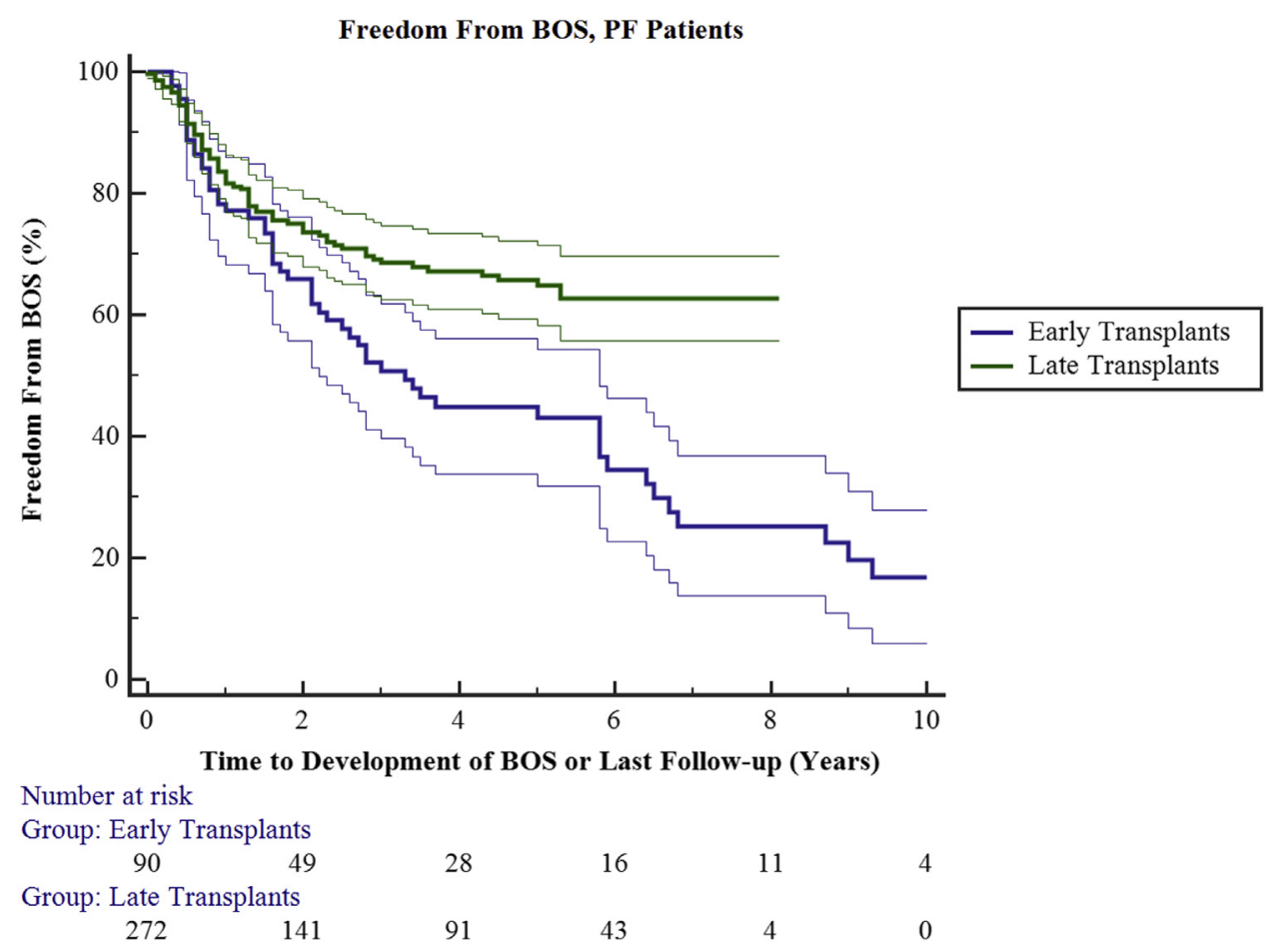

FIGURE E3. Freedom from bronchiolitis obliterans syndrome $(B O S)$ for patients with interstitial pulmonary fibrosis, separated by group. Early transplant (pre-las) and late transplant (post-las) $95 \%$ confidence limits are represented by the thin lines. PF, Pulmonary fibrosis.

TABLE E1. Overall patient survival including patients at risk at 5-year intervals and mean survival with $95 \%$ confidence intervals, grouped by disease process

\begin{tabular}{lcccccc}
\hline \multicolumn{1}{c}{ Disease } & $\begin{array}{c}\text { Number } \\
\text { at risk (5 y) }\end{array}$ & $\begin{array}{c}\text { Number at } \\
\text { risk (10 y) }\end{array}$ & $\begin{array}{c}\text { Number at } \\
\text { risk (15 y) }\end{array}$ & $\begin{array}{c}\text { Number at } \\
\text { risk (20 y) }\end{array}$ & $\begin{array}{c}\text { Mean } \\
\text { survival (y) }\end{array}$ & $\begin{array}{c}\text { 95\% confidence } \\
\text { interval }\end{array}$ \\
\hline Cystic fibrosis & 121 & 68 & 29 & 7 & 13.1 & $11.5-14.7$ \\
$\begin{array}{l}\text { Chronic obstructive } \\
\text { pulmonary disease }\end{array}$ & 260 & 135 & 63 & 13 & 10.2 & $9.3-11.0$ \\
Interstitial pulmonary fibrosis & 145 & 46 & 10 & 2 & 12.2 & $10.7-13.6$ \\
Other & 183 & 102 & 49 & 21 & 1.2 & $10.0-12.4$ \\
\hline
\end{tabular}


TABLE E2. Early transplant patient survival including patients at risk at 5-year intervals and mean survival with $95 \%$ confidence intervals, grouped by disease process

\begin{tabular}{lcccccc}
\hline \multicolumn{1}{c}{ Disease } & $\begin{array}{c}\text { Number at } \\
\text { risk (5 y) }\end{array}$ & $\begin{array}{c}\text { Number at } \\
\text { risk (10 y) }\end{array}$ & $\begin{array}{c}\text { Number at } \\
\text { risk (15 y) }\end{array}$ & $\begin{array}{c}\text { Number at } \\
\text { risk (20 y) }\end{array}$ & $\begin{array}{c}\text { Mean } \\
\text { survival (y) }\end{array}$ & $\begin{array}{c}\text { 95\% confidence } \\
\text { interval }\end{array}$ \\
\hline Cystic fibrosis & 76 & 58 & 29 & 7 & 12.2 & $10.3-14.1$ \\
$\begin{array}{l}\text { Chronic obstructive } \\
\text { pulmonary disease }\end{array}$ & 193 & 124 & 63 & 13 & 10.0 & $9.1-10.9$ \\
Interstitial pulmonary fibrosis & 48 & 31 & 10 & 2 & 9.1 & $7.3-10.9$ \\
Other & 132 & 90 & 49 & 21 & 10.2 & $8.9-11.5$ \\
\hline
\end{tabular}

TABLE E3. Late transplant patient survival including patients at risk at 2-year intervals and mean survival with $95 \%$ confidence intervals, grouped by disease process

\begin{tabular}{lcccccc}
\hline \multicolumn{1}{c}{ Disease } & $\begin{array}{c}\text { Number at } \\
\text { risk (2 y) }\end{array}$ & $\begin{array}{c}\text { Number at } \\
\text { risk (4 y) }\end{array}$ & $\begin{array}{c}\text { Number at } \\
\text { risk (6 y) }\end{array}$ & $\begin{array}{c}\text { Number at } \\
\text { risk (8 y) }\end{array}$ & $\begin{array}{c}\text { Mean } \\
\text { survival (y) }\end{array}$ & $\begin{array}{c}\mathbf{9 5} \% \text { confidence } \\
\text { interval }\end{array}$ \\
\hline Cystic fibrosis & 78 & 51 & 35 & 24 & 7.8 & $6.9-8.8$ \\
$\begin{array}{l}\text { Chronic obstructive } \\
\text { pulmonary disease }\end{array}$ & 121 & 84 & 50 & 27 & 7.1 & $6.3-7.9$ \\
Interstitial pulmonary fibrosis & 186 & 121 & 72 & 38 & 8.6 & $7.9-9.2$ \\
Other & 87 & 63 & 41 & 27 & 8.1 & $7.3-9.0$ \\
\hline
\end{tabular}

